Article

\title{
A Novel Three-Phase Six-Switch PFC Rectifier with Zero-Voltage-Switching and Zero-Current-Switching Features
}

\author{
Chun-Wei Lin ${ }^{1, *}$, Chang-Yi Peng ${ }^{2}$ and Huang-Jen Chiu ${ }^{1}$ \\ 1 Department of Electronic and Computer Engineering, \\ National Taiwan University of Science and Technology, Taipei 10607, Taiwan; hjchiu@mail.ntust.edu.tw \\ 2 Department of Electrical Engineering, Chung-Yuan Christian University, Taoyuan 32023, Taiwan; \\ Kingpeng50@yahoo.com.tw \\ * Correspondence: d10402204@mail.ntust.edu.tw; Tel.: +886-937-880-025
}

Received: 18 March 2019; Accepted: 19 March 2019; Published: 22 March 2019

\begin{abstract}
A novel three-phase power-factor-correction (PFC) rectifier with zero-voltage-switching (ZVS) in six main switches and zero-current-switching (ZCS) in the auxiliary switch is proposed, analyzed, and experimentally verified. The main feature of the proposed auxiliary circuit is used to reduce the switching loss when the six main switches are turned on and the one auxiliary switch is turned off. In this paper, a detailed operating analysis of the proposed circuit is given. Modeling and analysis are verified by experimental results based on a three-phase $7 \mathrm{~kW}$ rectifier. The soft-switched PFC rectifier shows an improvement in efficiency of $2.25 \%$ compared to its hard-switched counterpart at $220 \mathrm{~V}$ under full load.
\end{abstract}

Keywords: three-phase rectifier; PFC; switch-mode rectifier; ZVS; ZCS

\section{Introduction}

Power electronic converters play a critical role in the energy industry due to their ability to optimally control and condition the power they deliver to a load. In addition, they are required to control and condition the power they draw from energy sources to support their optimal operation. This is achieved by compliance to EMI and harmonic standards such as EN6100-3-2 and efficiency standards such as 80Plus [1]. Soft-switching technologies are a primary enabler for improving efficiency by minimizing switching losses and reducing EMI and harmonics by "soft" ending the edges of the switching transitions [2-12]. References [8] and [9] report soft-switching techniques that includes zero-voltage-switching (ZVS) and zero-current-switching (ZCS). Three-phase rectifiers with active power-factor-correction (PFC) control achieve an improved power factor and lower harmonic content [10-13]. Active PFC rectifiers using a boost (current source) front end achieve better input current wave-shaping and lower harmonic distortion compared to their buck-derived counterparts [14]. Three single-phase PFC rectifiers are used in [15] to synthesize a three-phase PFC rectifier. Reference [16] reports the use of space vector modulation (SVM) to achieve a high power factor in a three-phase six-switch rectifier. Soft-switching techniques employed in three-phase rectifiers are reported in [17-19] to improve efficiency and EMI performance. Soft-switching using a passive lossless snubber is presented in [17]. Although this approach can improve the efficiency, the circuit suffers from higher component stress. In [18], an active snubber is used to achieve soft-switching at the expense of higher control complexity and switching stress in the auxiliary switch. In [19-22], the zero-voltage-transition and control technique was applied in a three-phase PFC rectifier. Although the main switches can achieve ZVS at turn-on, the auxiliary switch was hard-switched operated at turn-off. 
A conventional three-phase six-switch PFC rectifier is shown in Figure 1. A novel soft-switched three-phase active rectifier using an active auxiliary circuit is proposed in this paper. The principal performance improvement is the achievement of ZVS at turn-on for the six rectifier switches and ZCS at turn-off for the one auxiliary switch. A detailed description of the operation of the proposed soft-switched rectifier is presented in Section 2. Validation of the design through simulation and experimental results are shown in Section 3 followed by concluding remarks in Section 4 .

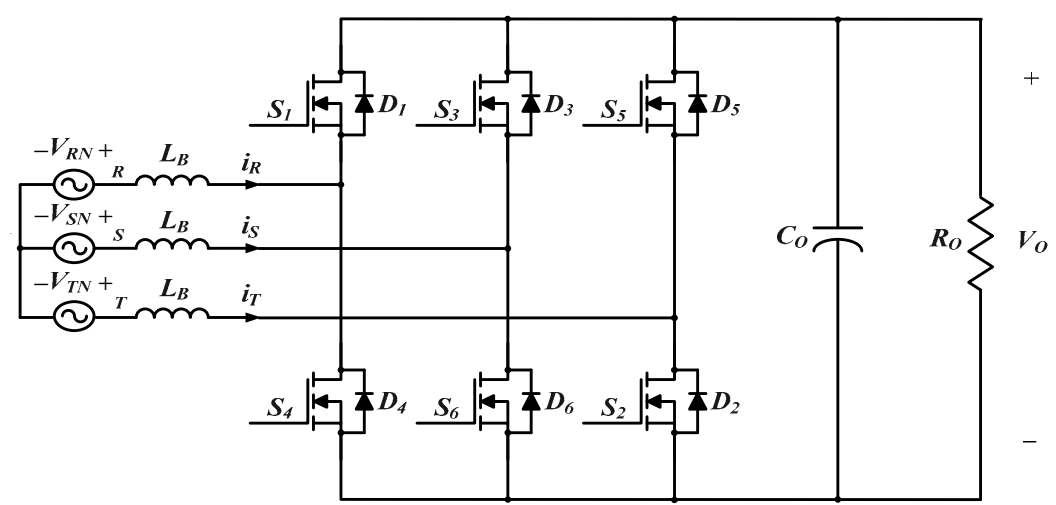

Figure 1. A conventional three-phase six-switch power-factor-correction (PFC) rectifier.

\section{Proposed Three-Phase Six-Switch Soft-switching PFC Rectifier}

The proposed three-phase six-switch soft-switching PFC rectifier is shown in Figure 2. The circuit inside the dotted box is a soft-switching assist circuit to achieve ZVS in the main switches and ZCS in the auxiliary switch. The soft-switching assist circuit consists of the auxiliary switch $S_{A}$, resonant inductor $L_{R}$, transformer $T_{r}$, barrier diode $D_{R 1}$, clamp circuit $R_{C}-D_{C}-C_{C}$, and resonant capacitor (the capacitance employs the parasitic capacitance of main switch).

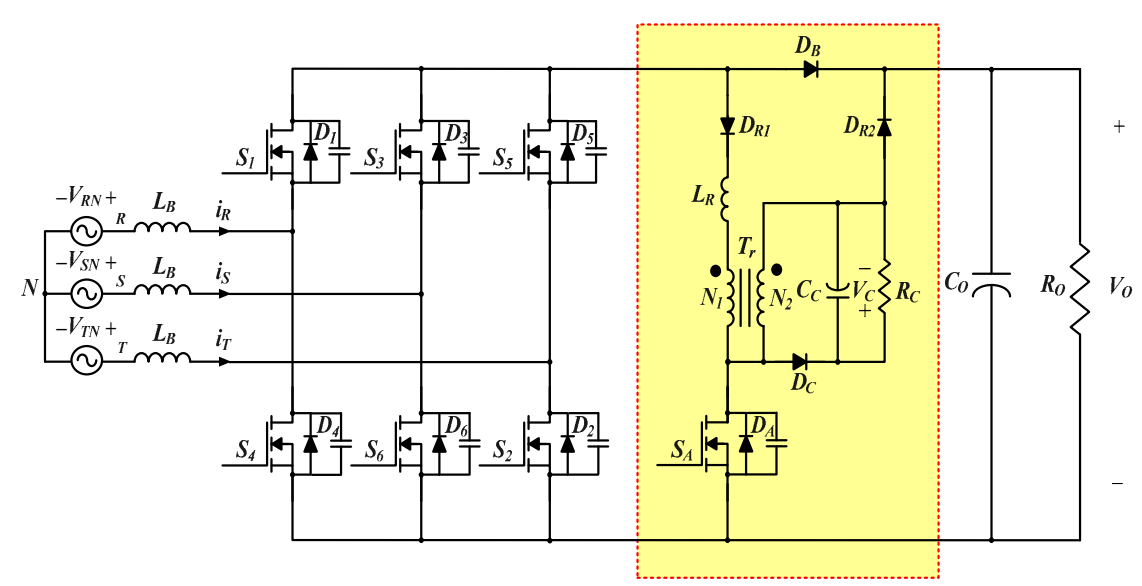

Figure 2. The circuit of the proposed soft-switching PFC rectifier.

Three phase line voltages $V_{R N}, V_{S N}, V_{T N}$ for a balanced three-phase system are shown in Figure 3. The $60^{\circ}$ symmetry in the three-phase voltages is evident from Figure 3 . The operation of the three-phase PFC using the $60^{\circ}$ symmetry is described in detail in [11]. 


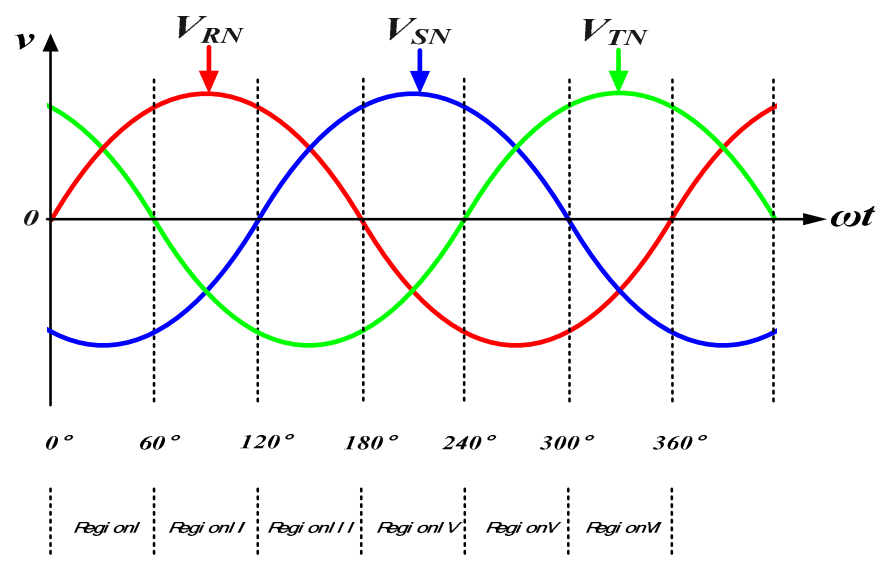

Figure 3. The line cycle in three-phase balance power system.

In order to simplify the analysis, Interval $1\left(0^{\circ}-60^{\circ}\right)$ can be selected for the analysis of the switching cycles as the operation over the rectifier is identical in the other $60^{\circ}$ segments. The following assumptions are made to support the operating analysis:

(1) Input inductance $L_{B}$ is large enough to allow the input current to be considered as a current source over a switching period;

(2) Input capacitance $C_{L}$ is large enough to be equivalent to the ideal voltage source $V_{O}$; and

(3) The output capacitance of the clamp circuit $C_{C}$ is large enough to allow its voltage $V_{C}$ to be considered a voltage source over a switching period.

Under the assumptions listed above, the simplified circuit diagram is shown in Figure 4 and the voltage polarity and current direction for each main component are defined.

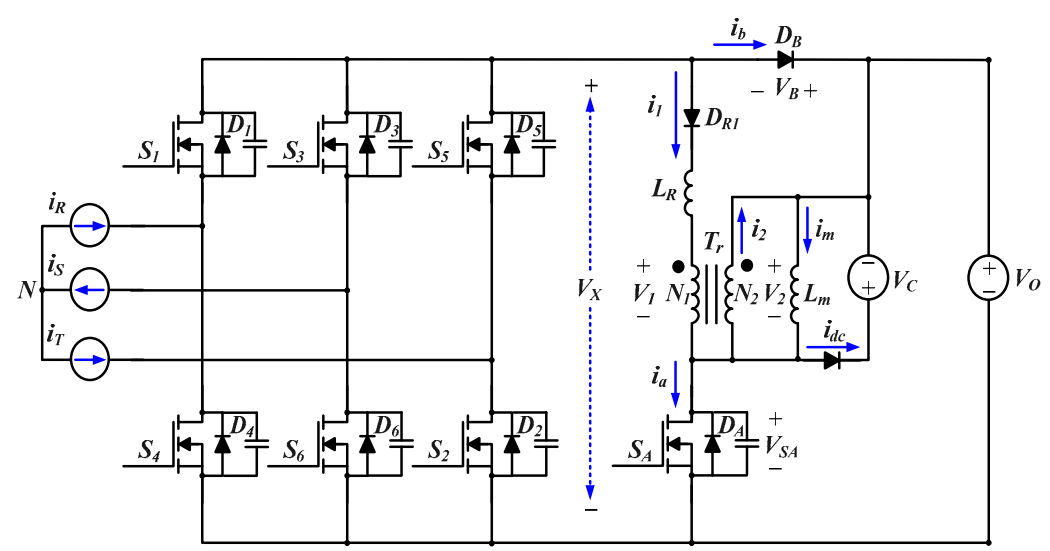

Figure 4. The simplified circuit of the proposed soft-switched rectifier.

A detailed description of circuit operation is provided in this section. The key waveforms of the circuit for Interval 1 are shown in Figure 5, and equivalent circuits for each operating mode are shown in Figure 6. There are 12 operating modes to be analyzed over a switching cycle.

\subsection{Mode 0: $\left(t \leqq T_{0}\right)$}

This mode is based on the analysis of the switching cycle in Interval $1\left(V_{R N}>0, V_{T N}>0\right.$, and $\left.V_{S N}<0\right)$. Before $T_{0}$, as in Figure $6 a$, the diode $D_{1}, D_{6}$, and $D_{5}$ are in the state of conduction. The main switches $S_{1}$ to $S_{6}$ and auxiliary switch $S_{A}$ are turned off. The currents $i_{R}$ and $i_{T}$ flow through diode $D_{B}$ to the load and return to the AC source as the current $i_{S}$. Under this condition, the voltage across the active rectifier bridge is $V_{X}=V_{O}$. 


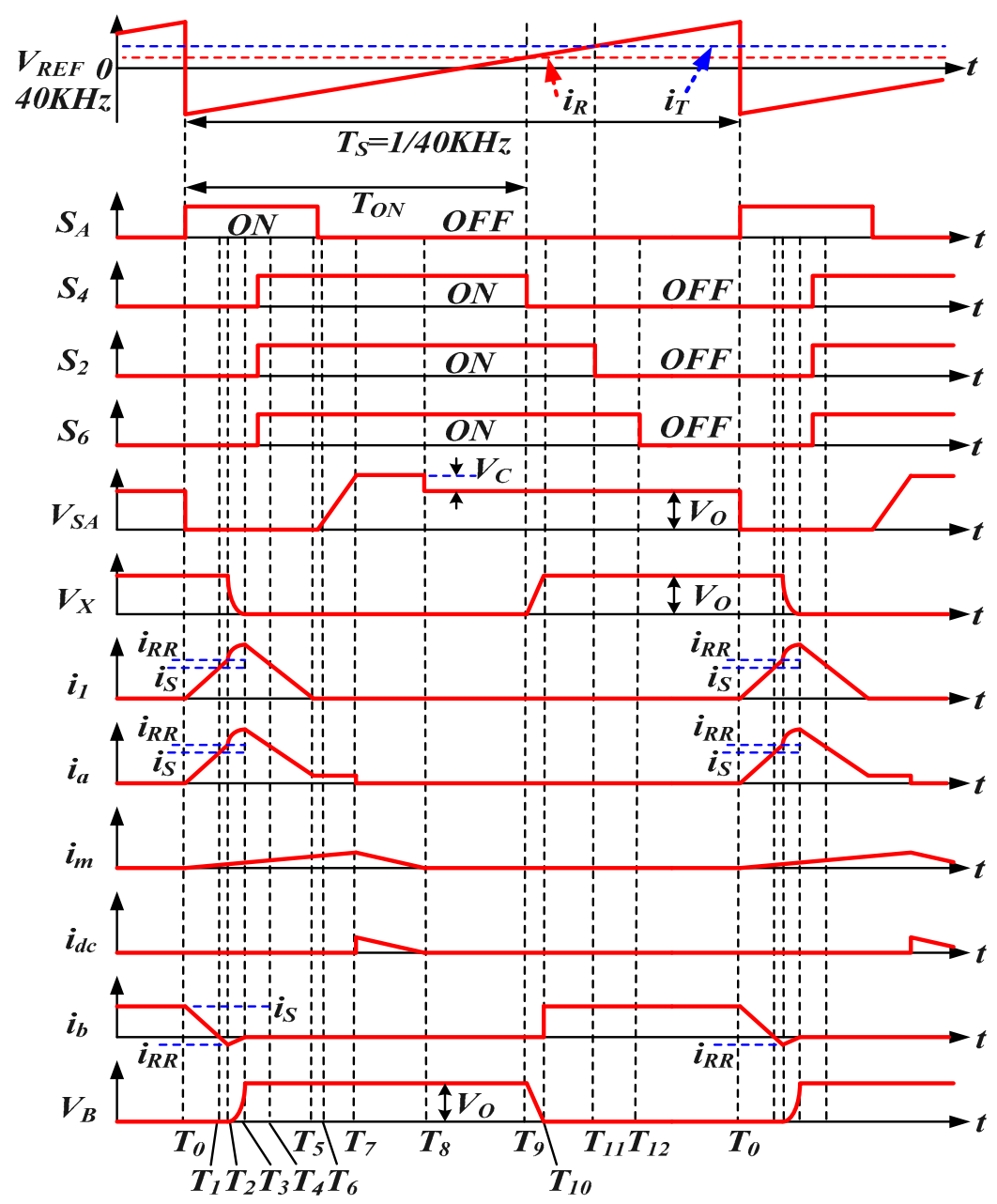

Figure 5. The key waveforms of the proposed soft-switched rectifier.

\subsection{Mode $1\left(T_{0}<t \leqq T_{1}\right)$}

At $T_{0}$, the auxiliary switch $S_{A}$ is turned on to go into Mode 1 . The current $i_{1}$ of resonant inductor $L_{R}$ starts to increase, and current $i_{1}$ flows through the primary winding $N_{1}$ of the transformer $T_{r}$. The induced current $i_{2}$ and excitation current $i_{m}$ outflow through secondary coil $N_{2}$, as shown in Figure $6 \mathrm{~b}$. The voltage on the seconding winding $N_{2}$ is the output voltage $V_{O}$. The voltage $V_{1}$ and $V_{2}$ across the windings of transformer $T_{r}$ are obtained as follows:

$$
\begin{gathered}
V_{2}=V_{O} \\
V_{1}=\frac{N_{1}}{N_{2}} V_{2}=n V_{O}
\end{gathered}
$$

The current in the resonant inductor $i_{1}$ increases linearly with the slope given by

$$
\frac{d i_{1}}{d t}=\frac{V_{O}-V_{1}}{L_{R}}=\frac{V_{O}-n V_{O}}{L_{R}}=(1-n) \frac{V_{O}}{L_{R}}
$$

Similarly to $i_{1}$, the excitation current $i_{m}$ also displays a linear increase, and the slope is

$$
\frac{d i_{m}}{d t}=\frac{V_{O}}{L_{m}}
$$


When the current $i_{1}$ ascends to $i_{S}$ current, this mode ends. The time interval is given as below:

$$
t_{01}=\frac{i_{s}}{V_{o}(1-n) L_{R}}
$$

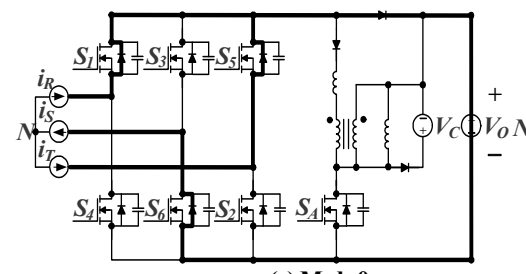

(a) Mode 0

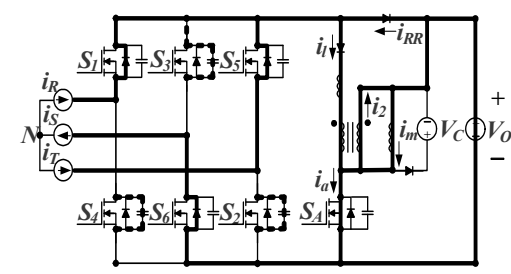

(d)Mode 3

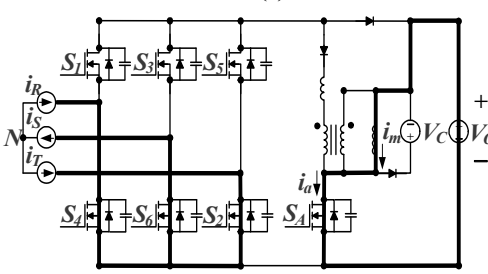

(g) Mode 6

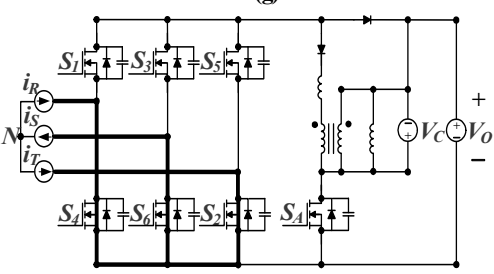

(j) Mode 9

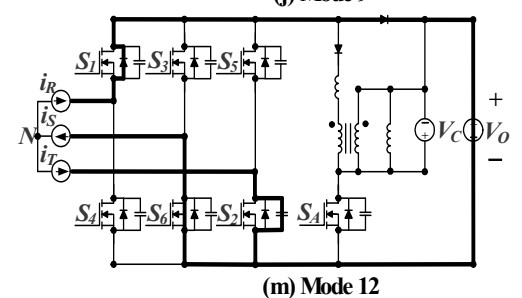

Figure 6. Operation modes of the proposed soft-switched rectifier.

\subsection{Mode $2\left(T_{1}<t \leqq T_{2}\right)$}

At $t=T_{1}$, the DC link diode current $i_{b}$ reaches zero. The reverse recovery current of diode $D_{B}$ flows through diode $D_{B}$ in a negative direction. The resonant inductor current keeps increasing, as shown in Figure 6c.

\subsection{Mode $3\left(T_{2}<t \leqq T_{3}\right)$}

At $t=T_{2}$, the parasitic capacitance of diode $D_{b}$ along with the resonant capacitor $C_{R}$, which includes the parasitic capacitor of the main switches and the resonant inductor $L_{R}$, start resonating, as 
shown in Figure $6 \mathrm{~d}$. When the equivalent voltage $V_{X}$ of the main switch is decreased to zero at $t=T_{3}$, the mode ends. The equivalent voltage $V_{X}$ and resonant current $i_{1}$ are shown in Equations (6) and (7).

$$
\begin{gathered}
V_{X}=V_{O}-(1-n) V_{O}\left(1-\cos \left(\omega_{R} t\right)\right) \\
i_{1}=i_{S}+i_{R R}+\frac{(1-n) V_{O}}{Z_{C}} \sin \left(\omega_{R} t\right) \\
C_{R}=C_{2}+C_{3}+C_{4} \\
\omega_{R}=\frac{1}{\sqrt{L_{R}\left(C_{R}+C_{b}\right)}} \\
Z_{C}=\sqrt{\frac{L_{R}}{C_{R}+C_{b}}}
\end{gathered}
$$

\subsection{Mode 4: $\left(T_{3}<t \leqq T_{4}\right)$}

When $t>T_{3}$, the bridge rectifier voltage $V_{X}$ is decreased to zero and the auxiliary switch $S_{A}$ continues to conduct. The corresponding equivalent circuit is shown in Figure 6e. The body diodes $D_{4}$, $D_{3}$, and $D_{2}$ of the main switches $S_{4}, S_{3}$, and $S_{2}$ are conducting. Turning on the main switches $S_{4}, S_{6}$, and $S_{2}$ when the bridge voltage reaches zero achieves ZVS turn-on. The detection circuitry to turn on the main switches at zero voltage also enables the minimization of duty-cycle loss and, thus, loss of efficiency. After the main switches turn on at ZVS, the resonant inductor current $i_{1}$ decreases linearly with the slope given by Equation (11). When the current of the main switches $S_{4}$ and $S_{2}$ reaches zero at $t=T_{4}$, the mode ends.

$$
\frac{d i_{1}}{d t}=-\frac{n V_{O}}{L_{R}}
$$

\subsection{Mode 5: $\left(T_{4}<t \leqq T_{5}\right)$}

As shown in Figure 6f, when $t>T_{4}$, then $S_{4}, S_{6}$, and $S_{2}$ keep conducting. The current $i_{l}$ is continuously decreased to zero until $t=T_{5}$.

\subsection{Mode 6: $\left(T_{5}<t \leqq T_{6}\right)$}

When $t>T_{5}$, the input currents $i_{R}$ and $i_{T}$ flow through the main switches $S_{4}$ and $S_{2}$, as shown in Figure $6 \mathrm{~g}$. When the current $i_{a}$ flows through the auxiliary switch $S_{A}$, it consists mostly of the magnetizing current, $i_{m}$, of the transformer. If the magnetizing inductance $L_{m}$ is designed to be relatively large, the current $i_{a}$ of the auxiliary switch $S_{A}$ is extremely close to zero. When $T_{5}<t \leqq T_{6}$, the auxiliary switch is set to be turned off so that it can effectively achieve the purpose of ZCS.

\subsection{Mode 7: $\left(T_{6}<t \leqq T_{7}\right)$}

When $t=T_{6}$, the auxiliary switch $S_{A}$ is turned off, as shown in Figure 6h. Subsequently, the magnetizing current $i_{m}$ of the transformer charges the parasitic capacitance $C_{o s s} 1$ of the auxiliary switch $S_{A}$ so that the auxiliary switch voltage will increase continuously.

\subsection{Mode 8: $\left(T_{7} \leqq t \leqq T_{8}\right)$}

At $t=T_{7}$, the auxiliary switch voltage $V_{S A}$ increases to $V_{O}+V_{C}$ and the clamp diode $D_{C}$ is conducting. The magnetizing current $i_{m}$ discharges through the clamp circuit $D_{C}-V_{C}$, as shown in Figure 6i. The slope of the excitation current in this mode is given by

$$
\frac{d i_{m}}{d t}=-\frac{V_{C}}{L_{m}}
$$


2.10. Mode 10: $\left(T_{8} \leqq t \leqq T_{9}\right)$

At $t=T_{8}$, the magnetizing current $i_{m}$ is decreased to zero which resets the transformer, as shown in Figure 6j.

\subsection{Mode 10: $\left(T_{9}<t \leqq T_{10}\right)$}

At $t=T_{9}$, the main switch $S_{4}$ is turned off. The input current $i_{R}$ charges the parasitic capacitance of the main switch $S_{4}$ and the equivalent voltage $V_{X}$ of the main switch is increased, as shown in Figure $6 \mathrm{k}$.

\subsection{Mode 11: $\left(T_{10} \leqq t \leqq T_{11}\right)$}

At $t=T_{10}$, the equivalent voltage $V_{X}$ of the main switch is increased to $V_{O}$ and the diode $D_{B}$ is conducting as shown in Figure 6l. Subsequently, the antiparallel diode $D_{1}$ of the main switch $S_{1}$ is conducting. The input current $i_{R}$ flows through diodes $D_{1}$ and $D_{B}$ and flows back from $i_{S}$ through the load.

\subsection{Mode 12: $\left(T_{11} \leqq t \leqq T_{12}\right)$}

At $t=T_{11}$, the main switch $S_{2}$ is turned off. The input current $i_{T}$ starts to charge the parasitic capacitance of the main switch $S_{2}$, as shown in Figure $6 \mathrm{~m}$.

\section{Experimental Verifications}

Based on the design described, a prototype was built. When the line voltage in the three-phase input was $220 \mathrm{~V}$, namely, the phase voltage was $127 \mathrm{~V}$, the switching frequency $40 \mathrm{kHz}$, and the output load $7 \mathrm{~kW}$, then the measured waveforms for three-phase $\mathrm{V}_{R N}, \mathrm{~V}_{S N}, \mathrm{~V}_{T N}$, line voltage and the line current were at low line and full load. The current waveform, as in Figure 7, is practically sinusoidal with low THD and a high power factor (the A-THD is shown in Figure 8 and power factor is shown in Figure 9).

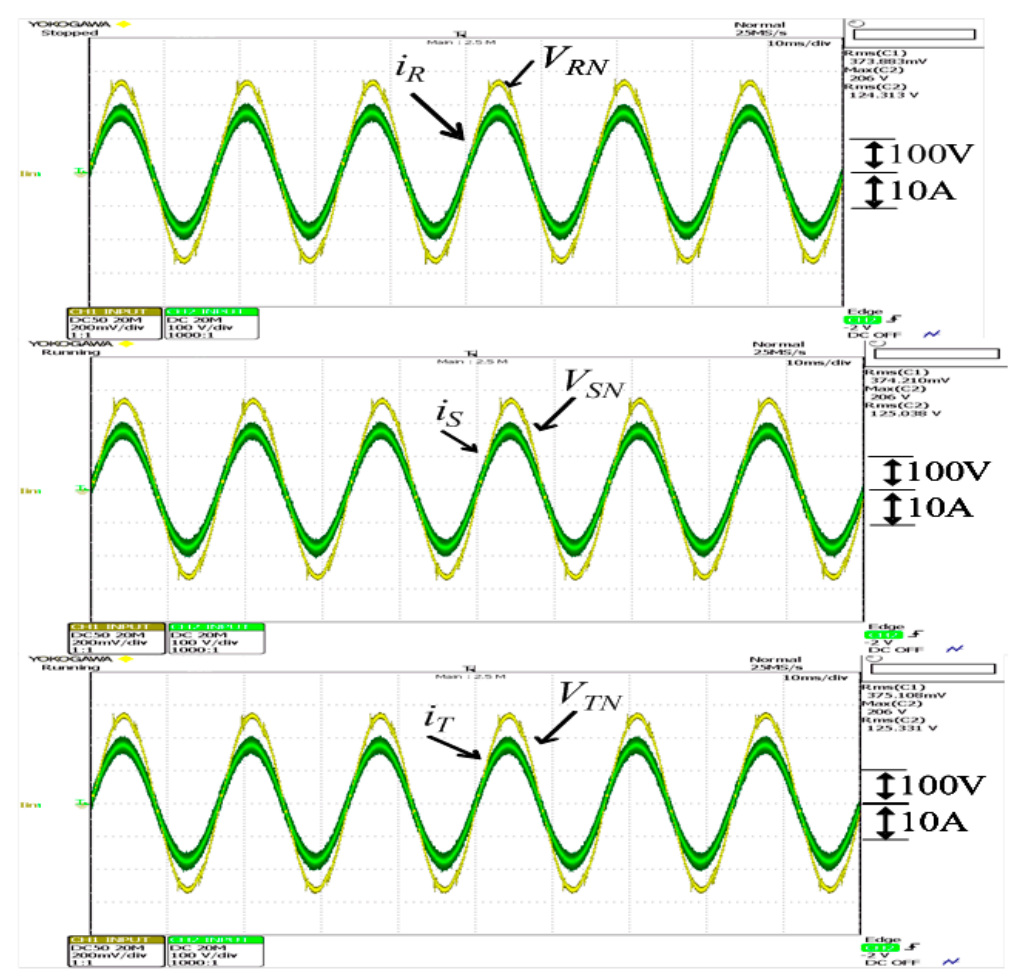

Figure 7. Measured waveforms of input voltage and input current at full load. 


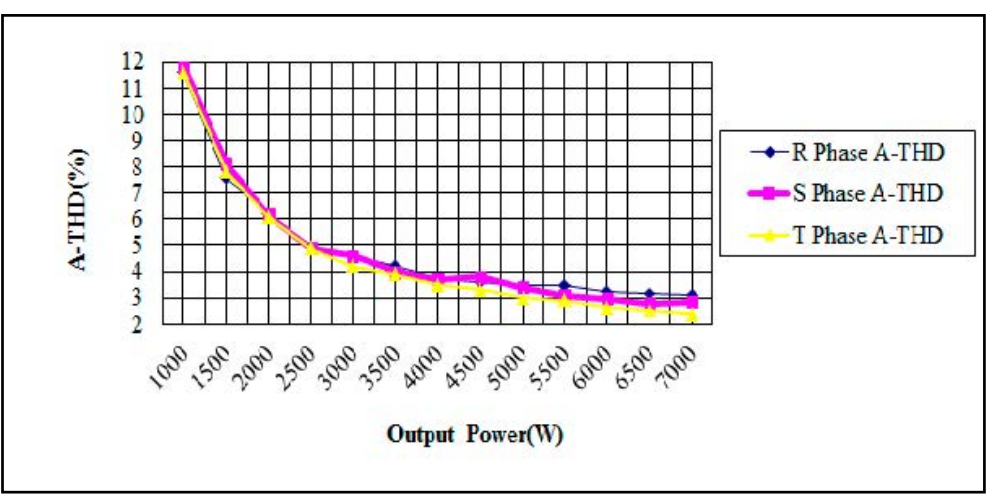

Figure 8. A-THD measured results.

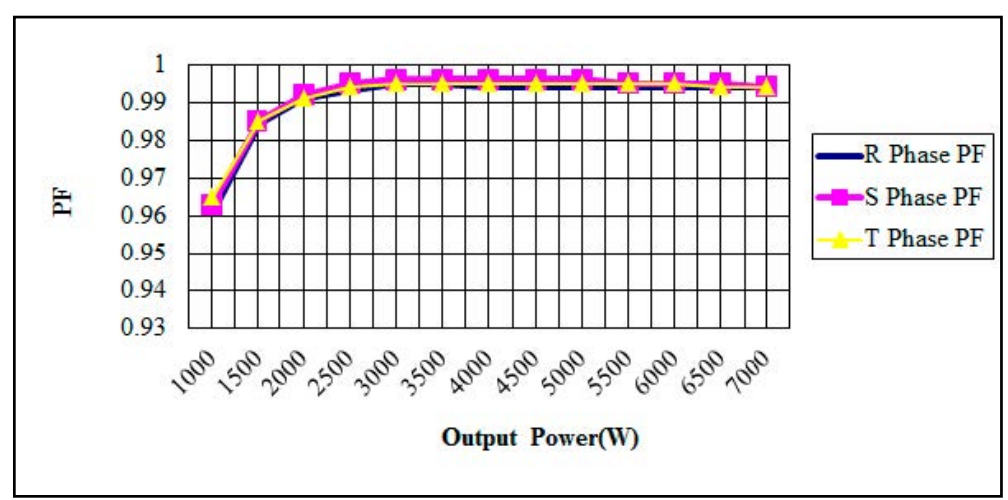

Figure 9. Power factor measured results.

Figure 10 shows the simulation waveforms using Isspice at half load and full load. It can be seen that the main switches $S_{4}$ and $S_{2}$ on the bottom sides turned on when their $V_{X}$ was down to zero by the resonant circuit, after the auxiliary switch $S_{A}$ was turned on.

Measured waveforms of the gate drive signals and voltage across the main switch are shown in Figure 11. The captured waveforms indicate the need to turn on the auxiliary switch $S_{A}$ before the turning on the main switches $S_{4}$ and $S_{2}$ to achieve ZVS.

As shown in Figure 12, when the current $i_{1}$ of resonant inductor $L_{R}$ decreases to zero, the auxiliary switch $S_{A}$ can be turned off under ZCS conditions.

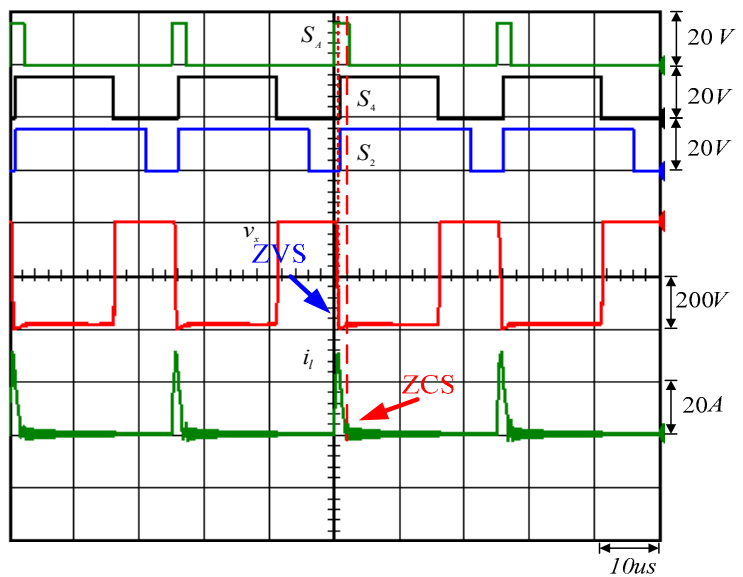

(a)

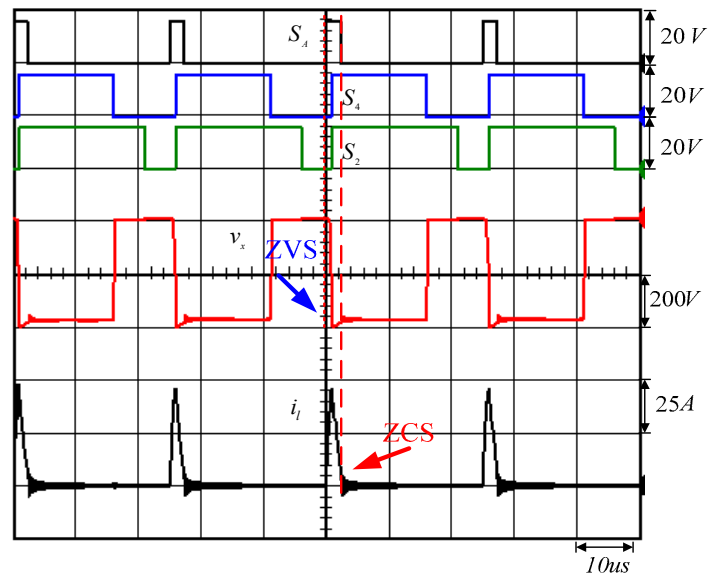

(b)

Figure 10. Simulation of key waveforms of the main switch voltage $V_{X}$ and current $i_{l}$ at (a) half load and (b) full load. 


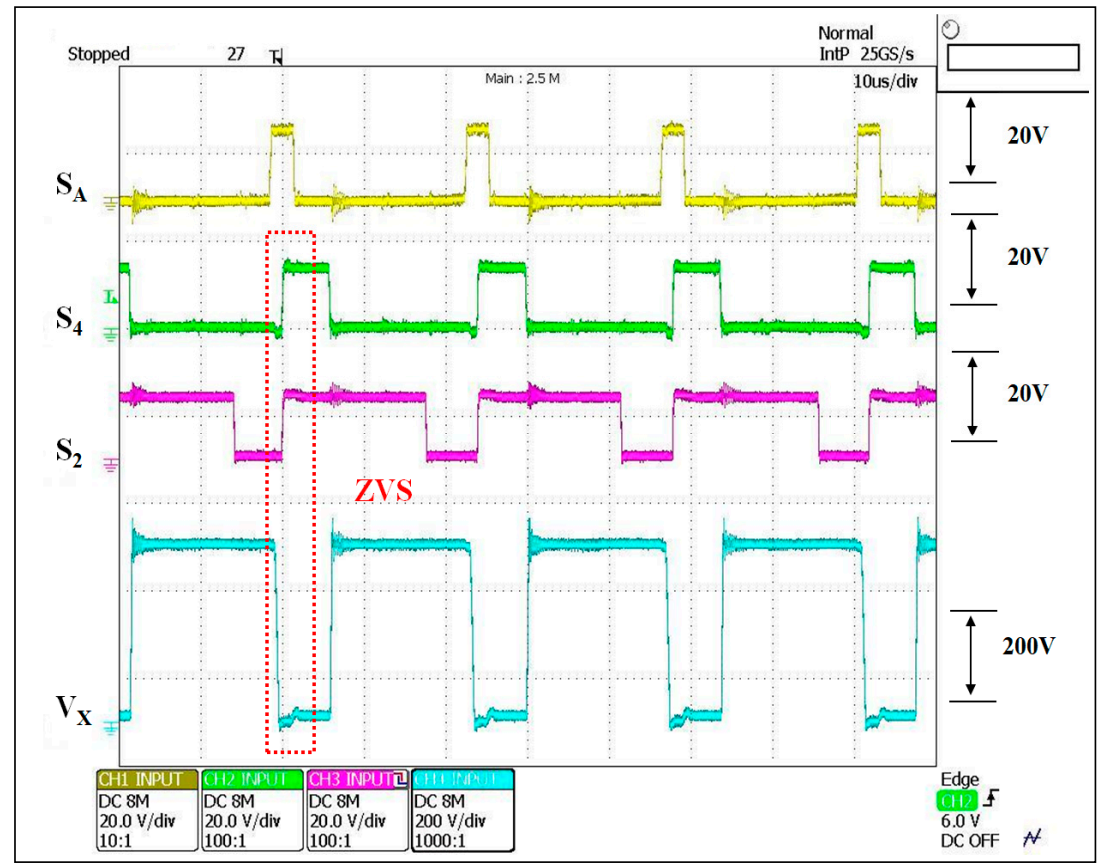

Figure 11. Measured waveforms of drive signal and voltage for the main switch of the soft-switched rectifier.

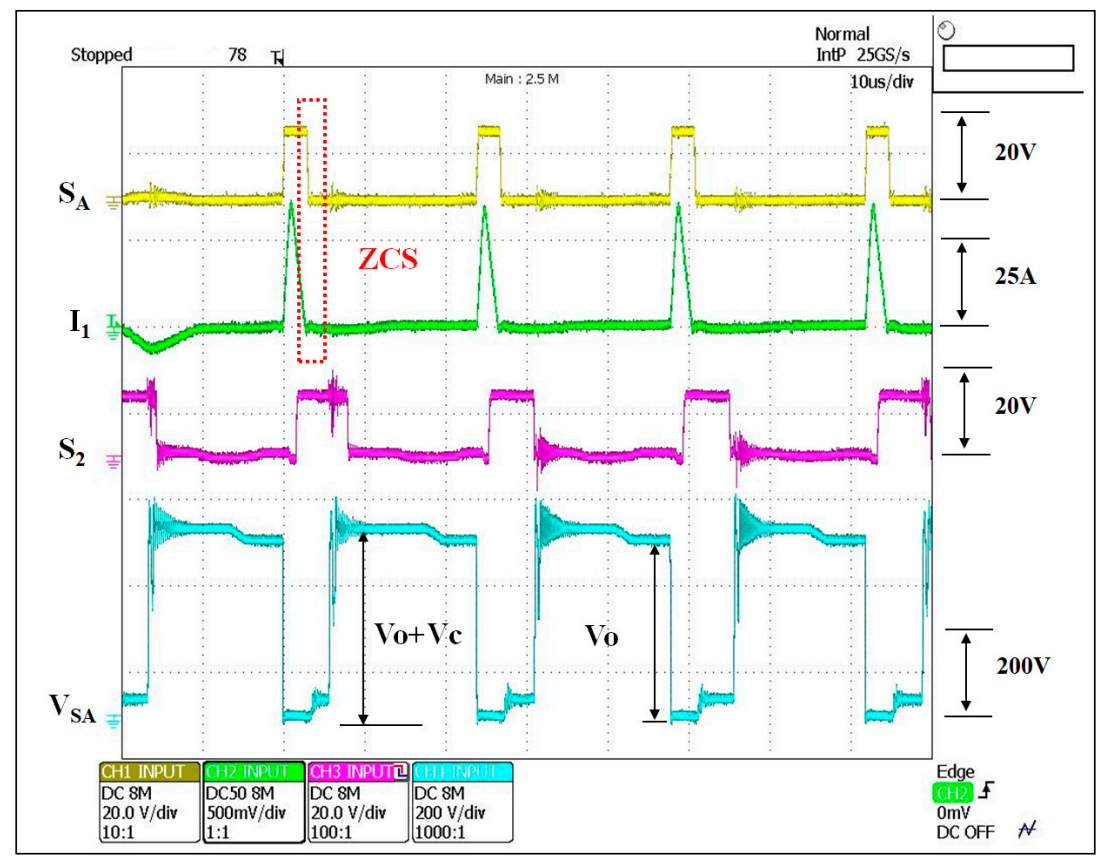

Figure 12. Measured waveforms of drive signal and resonant current for the main switch of the soft-switched rectifier.

A comparison between the hard-switched and proposed soft-switched rectifier was performed at a load of $7 \mathrm{~kW}$ over an input voltage range of 190-250 V. The hard-switched rectifier was tested by simply disabling the soft-switch assist circuitry. Figure 13 shows the efficiency improvement from the soft-switched rectifier. The largest efficiency difference between hard-switch and soft-switch rectifier was $2.55 \%$ when the input line voltage was $220 \mathrm{~V}$, and Figure 14 shows the soft-switched rectifier efficiency from $1-7 \mathrm{~kW}$. 


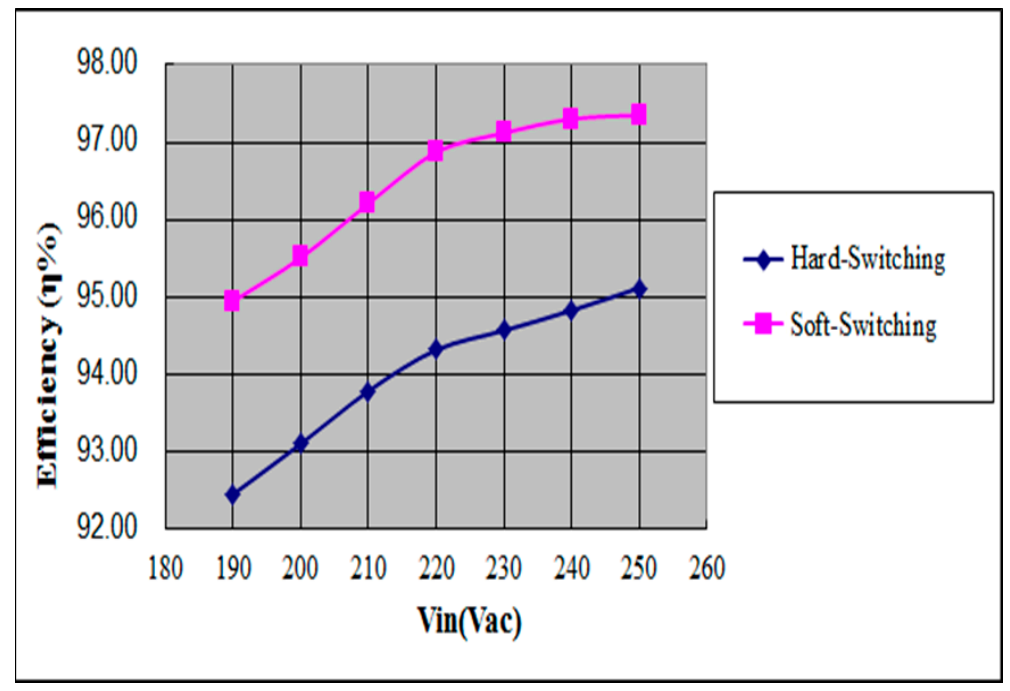

Figure 13. The efficiency comparison between hard-switching and soft-switching rectifier at $7 \mathrm{~kW}$ load.

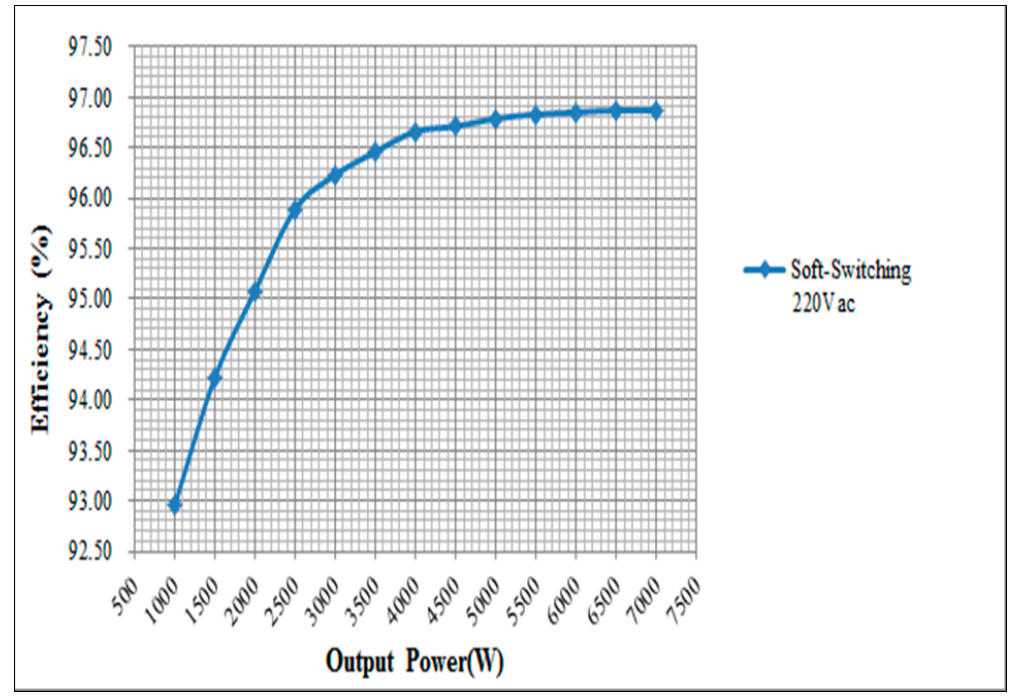

Figure 14. Measured efficiency from 1 to $7 \mathrm{~kW}$ with the soft-switched rectifier.

\section{Conclusions}

A novel three-phase rectifier with zero-voltage-switching and zero-current-switching features was proposed. The design has been validated with simulation and experimental data captured on a $7 \mathrm{~kW}$ three-phase rectifier prototype. Efficiency improvement between hard-switch and soft-switch rectifiers peaks at $2.55 \%$ when the input line voltage is $220 \mathrm{~V}$ at full load. Mathematical equations to explain circuit operation have been derived and analyzed under a sequence of operating modes. The experimental results have confirmed the proposed design of the soft-switched rectifier in achieving high efficiency, high power factor, and low THD.

Author Contributions: C.-W.L. and C.-Y.P. designed, debugged the system, built some part of hardware and performed the experiment. C.-W.L. also mainly responsible for preparing the paper. H.-J.C., supervised the design, analysis, experiment, and editing the paper.

Funding: The authors would like to acknowledge the financial support of the Ministry of Science and Technology of Taiwan through grant number NSC 103-2221-E-011 -064-MY3.

Conflicts of Interest: The authors declare no conflict of interest. 


\section{References}

1. Ecova Plug Load Solutions Website. 80 PLUS Certified Power Supplies and Manufacturers. Available online: http:/ / www.plugloadsolutions.com/80PlusPowerSupplies.aspx (accessed on 1 March 2019).

2. Kolar, J.W.; Friedli, T. The essence of three-phase PFC rectifier systems-Part I. IEEE Trans. Power Electron. 2013, 28, 176-198. [CrossRef]

3. Friedli, T.; Hartmann, M.; Kolar, J.W. The essence of three-phase PFC rectifier systems-Part II. IEEE Trans. Power Electron. 2014, 29, 543-560. [CrossRef]

4. Chang, C.H.; Cheng, C.A.; Chang, E.C.; Cheng, H.L.; Yang, B.E. An integrated high-power-factor converter with ZVS transition. IEEE Trans. Power Electron. 2016, 31, 2362-2371. [CrossRef]

5. Martins, M.L.S.; Hey, H.L. Self-commutated auxiliary circuit ZVT PWM converters. IEEE Trans. Power Electron. 2004, 19, 1435-1445. [CrossRef]

6. Bodur, H.; Bakan, A.F. A new ZVT-ZCT-PWM dc/dc converter. IEEE Trans. Power Electron. 2004, 19, 676-684. [CrossRef]

7. Ivanovic, B.; Stojiljkovic, Z. A novel active soft Switching snubber designed for boost converter. IEEE Trans. Power Electron. 2004, 19, 658-665. [CrossRef]

8. Moran, L.; Werlinger, P.; Dixon, J.; Wallace, R. A Series active power filter which compensates current harmonics and voltage unbalance simultaneously. In Proceedings of the IEEE PESC Conference, Atlanta, GA, USA, 18-22 June 1995; pp. 222-227.

9. Chang, Y. Boost Converter with Zero Voltage Main Switch and Zero Current Auxiliary Switches. U.S. Patent 6,498,463 B2, 24 December 2002.

10. Tsai, H.; Hsia, T.; Chen, D. A novel soft-switching bridgeless power factor correction circuit. In Proceedings of the European Power Electronics and Applications Conference, Aalborg, Denmark, 2-5 September 2007.

11. Jang, Y.; Jovanovic, M.M.; Fang, K.H.; Chang, Y.M. High-Power-Factor Soft-Switched Boost Converter. IEEE Trans. Power Electron. 2006, 21, 98-104. [CrossRef]

12. Tsai, H.Y.; Hsia, T.H.; Chen, D. A Family of Zero-Voltage Transition Bridgeless Power Factor CorrectionCircuits with a Zero-Current-Switching Auxiliary Switch. IEEE Trans. Ind. Electron. 2011, 58, 1848-1855. [CrossRef]

13. Wei, H.; Bataresh, I. Comparison of basic converter topologies for power factor correction. In Proceedings of the Southeastcon Conference, Orlando, FL, USA, 24-26 April 1998; pp. 348-353.

14. Mohan, N.; Undeland, T.M.; Robbins, W.P. Power Electronics Converters, Applications and Design, 2nd ed.; Wiley: New York, NY, USA, 1995.

15. Jiang, Y.; Mao, H.; Lee, F.C.; Borojevic, D. Simple high Performance three-phase boost rectifiers. In Proceedings of the IEEE Power Electronics Specialists Conference, Taipei, Taiwan, 20-25 June 1994; pp. 1158-1163.

16. Li, R.; Ma, K.; Xu, D. A novel 40 KW ZVS-SVM controlled three-phase boost PFC converter. In Proceedings of the IEEE Applied Power Electronics Conference and Exposition, Washington, DC, USA, 15-19 February 2009; pp. 376-382.

17. Hengchun, M.; Lee, C.Y.; Boroyevich, D.; Hiti, S. Review of high-performance three-phase power-factor correction circuits. IEEE Trans. Ind. Electron. 1997, 44, 437-446. [CrossRef]

18. Li, Q.; Zhou, X.; Lee, F.C. A novel ZVT three-phase rectifier/inverter with reduced auxiliary switch stresses and losses. In Proceedings of the IEEE PESC PESC'96, Baveno, Italy, 23-27 June 1996; pp. 153-158.

19. Vlatkovic, V.; Borojevic, D.; Lee, F.C.; Cuadros, C.; Gataric, S. A new zero-voltage transition, three-phase PWM rectifier/inverter circuit. In Proceedings of the IEEE PESC'93, Seattle, WA, USA, 20-24 June 1993; pp. 868-873.

20. Kennel, R.; Schröder, D. Predictive control strategy for converters. In Proceedings of the 3rd IFAC Symposium on Control in Power Electronics and Electrical Drives, Lausanne, Switzerland, 12-14 September 1983; pp. 415-422. 
21. Mercorelli, P.; Kubasiak, N.; Liu, S. Multilevel bridge governor by using model predictive control in wavelet packets for tracking trajectories. In Proceedings of the IEEE International Conference on Robotics and Automation, New Orleans, LA, USA, 26 April-1 May 2004; pp. 4079-4084.

22. Mercorelli, P.; Kubasiak, N.; Liu, S. Model predictive control of an electromagnetic actuator fed by multilevel PWM inverter. In Proceedings of the IEEE International Symposium on Industrial Electronics, Ajaccio, France, 4-7 May 2004; pp. 531-535.

(C) 2019 by the authors. Licensee MDPI, Basel, Switzerland. This article is an open access article distributed under the terms and conditions of the Creative Commons Attribution (CC BY) license (http:/ / creativecommons.org/licenses/by/4.0/). 